Ludmila Kosyanchuk, Nataly Kozak, Oksana Antonenko, Yury Nizelskii and Yury Lipatov

\title{
REACTION KINETICS AND MACROMOLECULE-METAL CHELATE COMPLEX FORMATION IN METAL CONTAINING SEMI- INTERPENETRATING POLYMER NETWORKS BASED ON CROSSLINKED POLYURETHANE AND LINEAR POLYMETHYLMETHACRYLATE
}

Institute of $\mathrm{M}$ acromolecular Chemistry of National Academy of Sciences of Ukraine, 48 Kharkov chaussee, $02160 \mathrm{Kiev}$, Ukraine

kozaksmalt@ukr.net, todos@ukrpack.net

Received: M ay 27, 2008

(c) Kosyanchuk L.,Kozak N .,A ntonenko O.,N izelskii Y.,Li patovY. 2008

\begin{abstract}
According to DSC and EPR data kinetics of formation of simultaneous semi-interpenetrating polymer networks based on crosslinked polyurethane and linear polymethylmethacrylate with 50:50 and 70:30 ratio obtained in the presence of $3 \mathrm{~d}$-metal chelates depends on type of metal. On the other hand system composition determines polyurethane or polymethylmethacrylate selection during formation of complexes with metal $\beta$-diketonates.
\end{abstract}

Keywords: simultaneous semi-interpenetrating polymer networks, polyurethane, polymethylmethacrylate, $\beta$-diketonates of $\mathrm{Fe}(3+), \mathrm{Cr}(3+)$ and $\mathrm{Cu}(2+)$, reaction kinetic, metal-polymer complex, DSC, EPR.

\section{Introduction}

Many of in situ formed binary polymer systems (interpenetrating polymer networks (IPNs), mixtures of linear polymers, etc.) are thermodynamically nonequilibrium due to the incomplete phase separation in these systems caused by the reaction kinetics and diffusion constraints. The higher are the reaction rates of the forming components the lower is the degree of the phase separation. The rates of chemical reactions of the both components formation are interrelated and depend on catalyst and/or initiator concentration, as well as on the system components ratio [1].

Phase separation in polymer systems like IPNs can be essentially affected by the specific interactions between the reacting components. The donor-acceptor bonds between polar groups of the system components, as well as the reaction kinetic, also contribute to the incompleteness of phase separation.
The phase separation in polymer blends may be restricted by the specific additives improving the compatibility of polymer system components (compatibilizers) due to the formation of chemical and donor-acceptor bonds between them [2-5]. The compatibility of polymer components can be improved by introducing various metal compounds as compatibilizers [6].

It is known [6] that many of the metal $\beta$-diketonates (chelates) are capable of strong specific donor-acceptor interaction with compounds containing polar groups. In polymer system these metal chelates act as the centers of complexation, which is accompanied by the increase of the concentration of the polymer polar groups around the coordination node. The type of the polymer functional groups forming complexes with metal chelate depends on the electron-donor ability of the functional groups as well as on the electron configuration of metal ion [7-9].

Additionally, metal chelates may significantly affect the reaction kinetics due to the known catalytic activity of metal $\beta$-diketonates in formation of one of the polymer blend components, such as polyurethane [6].

Taking into account the capability of metal chelate to form complexes with the components of the reaction system as well as the effect of metal chelate on the reaction kinetics and the degree of phase separation it becomes important to study the effect of metal chelates on the formation of simultaneous IPNs. The aim of the present work is to reveal some regularities of the kinetics of semiinterpenetrating polymer networks formation based on cross-linked polyurethane and linear poly (methyl methacrylate) under influence of $\mathrm{Fe}\left(3^{+}\right)-, \mathrm{Cr}\left(3^{+}\right)$- and $\mathrm{Cu}\left(2^{+}\right) \beta$-diketonates and to analyze complexation of these metal chelates with polymer components. 


\section{Experimental}

\subsection{Reagents and Semi-IPN s Preparation}

All reagents for the synthesis of polyurethane: olygo(propylene glycol (OPG-1000, Merck), mixture of 2,4- and 2,6-tolylene diisocyanate (TDI 65/35, BASF), 1,1,1-trimethylolpropane (TMP, Aldrich) were purified and dried. Methyl methacrylate (MMA, Merck) was washed to withdraw hydroquinone, then dried and distilled. Initiator of radical polymerization 2,2-azobis(isobutyronitrile) (AIBM, Merck) was recrystallized from methanol. Metal chelates (RIAP, Ukraine) of $\mathrm{Cu}(2+), \mathrm{Fe}(3+)$ and $\mathrm{Cr}(3+)$ were used as received.

The semi-interpenetrating polymer networks (semiIPNs) were obtained by simultaneous and parallel formation of crosslinked polyurethane (PU) and linear polymethylmethacrylate (PMMA). Iron acetyl acetonate $\left(\mathrm{Fe}(\mathrm{acac})_{3}\right)$, chromium acetyl acetonate $\left(\mathrm{Cr}(\mathrm{acac})_{3}\right)$, and copper ethyl acetoacetate $\left(\mathrm{Cu}(\text { eacac })_{2}\right)$ were added to reaction mixture each component in an amount of $1 \%$ by weight.

The crosslinked PU was synthesized from macrodiisocyanate based on the mixture of oligo(oxypropylene glycol) with molecular weight $\mathrm{M}=$ 1000 and tolylene diisocyanate (a mixture of 2,4-, 2,6tolylene diisocyanate $65 / 35$, wt $\%$ ), in the presence of 1,1,1-trimethylolpropane as crosslinking agent. Methylmethacrylate (MMA) was added to the reaction mixture together with dissolved polymerization initiator 2,2-aso-bis-butyronitrile with the concentration of $0.005 \mathrm{~mol} / \mathrm{l}$.

The simultaneous reactions of the crosslinkage of $\mathrm{PU}$ and radical-free polymerization of MMA were proceeding at $333 \mathrm{~K}$.

\subsection{Kinetic Experiments}

The formation kinetics of metal free semi-IPNs and semi-IPNs containing $\mathrm{Cr}(\mathrm{acac})_{3}$ were analyzed using a DAK-1-1A micro calorimeter. The kinetics of the formation processes of semi-IPN containing $\mathrm{Fe}(\mathrm{acac})_{3}$ or $\mathrm{Cu}(\mathrm{eacac})_{2}$ were analyzed using IR-spectroscopy by analyzing the decrease of the absorption bands intensity of $2270 \mathrm{~cm}^{-1}$ $(v, \mathrm{NCO})$ and $1600 \mathrm{~cm}^{-1}(v,>\mathrm{C}=\mathrm{C}<)$ polymer groups. The separation of the kinetic processes of urethane formation and MMA polymerization was accomplished according to the procedure described in [10].

To record the infrared spectra the reaction mixture was poured onto $\mathrm{KBr}$ plates. The spectra were obtained by using Specord IR-75 spectrophotometer.

The formation of the complexes of $\mathrm{Fe}(\mathrm{acac})_{3}$, $\mathrm{Cr}(\mathrm{acac})_{3}$ and $\mathrm{Cu}(\mathrm{eacac})_{2}$ with the semi-IPN components was analyzed by electron paramagnetic resonance (EPR) spectroscopy, using various paramagnetic probes.

\subsection{EPR Experiments}

EPR spectroscopic studies were carried out at $293 \mathrm{~K}$ using a 3-cm radio spectrometer PE-1306. The resonance frequency was measured by a ChS-54 frequency meter with a YaZCh-87 frequency converter. The field calibration was performed using 2,2-diphenyl1-picrylhydrazyl (DPPH) with $g$-factor of 2.0036 and $\mathrm{Mn}^{2+}$ doped $\mathrm{MgO}$ matrix with g-factor of 2.0015 .

Nitroxyl spin probe 2,2,6,6-tetramethyl-1-piperidinyloxy (TEMPO) was introduced into semi-IPN samples to be studied via diffusion of its saturated vapor at $308 \mathrm{~K}$ for $2 \mathrm{hs}$ with subsequent keeping at $293 \mathrm{~K}$ for $24 \mathrm{~h}$.

The values of the correlation time $(\tau)$ of nitroxyl probe TEMPO rotational diffusion in the range of its fast motion $\left(10^{-11}<\tau<10^{-9} \mathrm{~s}\right)$ was calculated according to [11] as follows:

$$
\tau(s)=6,65 \Delta H_{(+1)}\left(\sqrt{\frac{I_{+1}}{I_{-1}}}-1\right) 10^{-10}
$$

where $\Delta H_{(+1)}$ is width of the central component of TEMPO EPR-spectrum, and $I_{+l}$ and $I_{-l}$ are intensities of low-field and high-field components of the spectrum, correspondingly (Fig. 2j).

Complex paramagnetic probe, such as copper ethyl acetoacetate, proposed in [8] was used to detect the semiIPN functional groups that did not participate in complex formation with metal chelate modifier. This method uses the sensitivity of copper chelates electron-spin parameters to symmetry and chemical nature of $\mathrm{Cu}(2+)$ neighborhood. For this purpose, the semi-IPN samples were held in $0.02 \mathrm{M}$ solution of the probe in dichloromethane at $293 \mathrm{~K}$ for 60 minutes with subsequent drying under vacuum at the same temperature to ensure constant weight of each sample.

The electron-spin parameters ( $\boldsymbol{g}$ and $\boldsymbol{A}$ ) for $\mathrm{Cu}(\text { eacac })_{2}$ used as complex spin probe were calculated according to [12].

\section{Results and Discussion}

\subsection{Characteristics of the Formation Kinetics of Semi-Interpenetrating Polymer N etworks under the Effect of Metal Chelates}

The kinetics of formation of semi-IPN with PUto-PMMA weight ratio of 70:30 in the presence of $\mathrm{Fe}(\mathrm{acac})_{3}, \mathrm{Cr}(\mathrm{acac})_{3}$, and $\mathrm{Cu}(\text { eacac })_{2}$ has been studied. The data obtained were compared with the results of the study accomplished for the semi-IPN with the PU-toPMMA ratio of 50:50 [13]. $1 \%$ weight content of each of the above metal chelates was conditioned by the catalytic activity of these metal chelates in urethane 

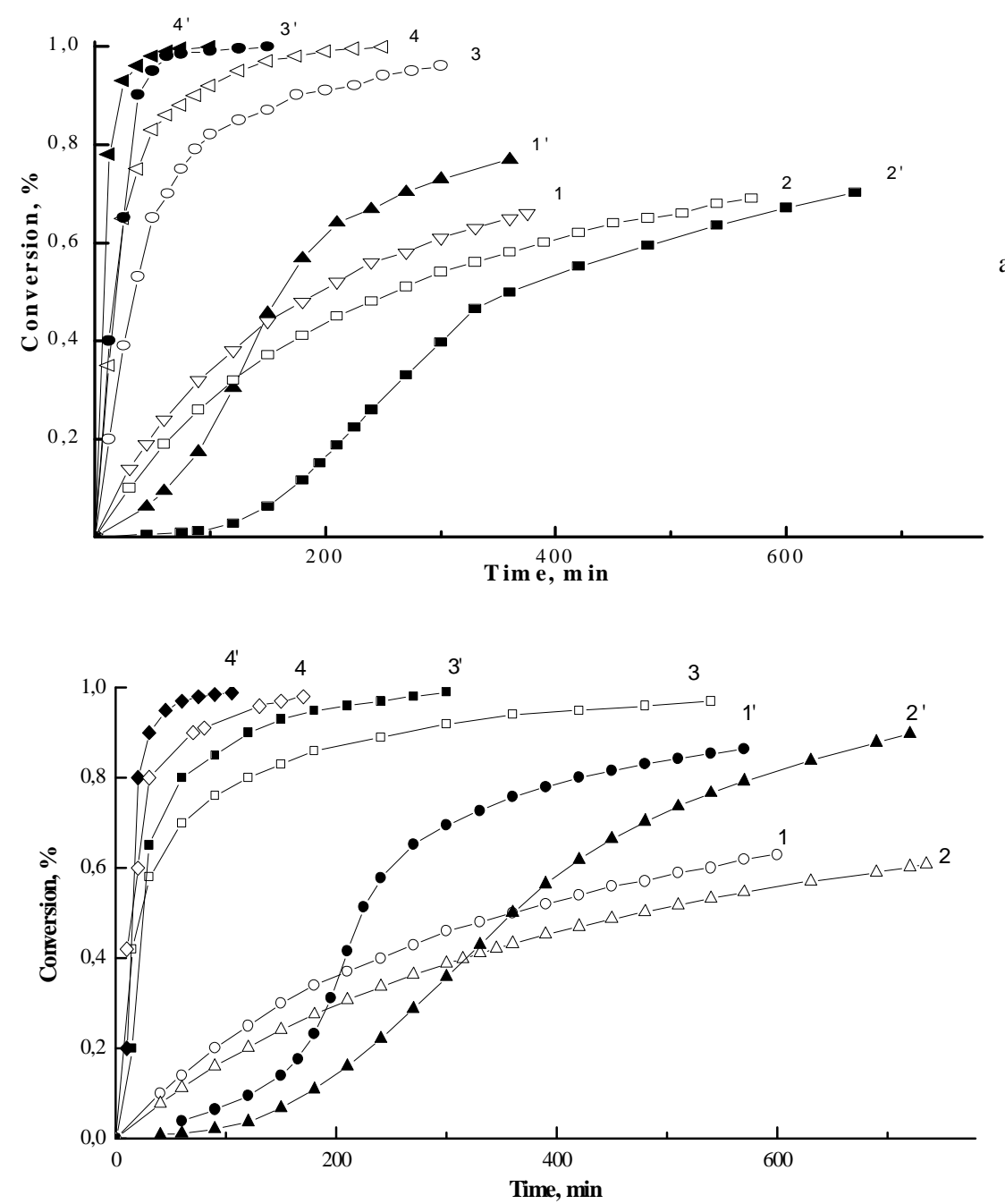

Fig. 1. Kinetics of formation of PU (1-4) and PMMA (1'-4') in the semi-IPN PU/PMMA ratios of 70:30 wt \% (a) and 50:50 (b) without metal chelates $\left(1,1^{\prime}\right)$ [14] and with chromium acetylacetonate $\left(3^{+}\right)\left(2,2^{\prime}\right)$, copper ethyl acetoacetate $\left(2^{+}\right)$

$\left(3,3^{\prime}\right)$, and iron acetylacetonate $\left(3^{+}\right)\left(4,4^{\prime}\right)$ in an amount of $1 \%$ by weight

formation reaction. Greater amounts of these metal chelates caused too high reaction rates while smaller amounts did not affect the kinetic characteristics.

Fig. 1a illustrates the kinetic characteristics of the formation of semi-IPN in the system with the PU-toPMMA ratio of 70:30, and Fig. $1 \mathrm{~b}$ illustrates the same characteristics but with the ratio of 50:50.

The characteristics presented in Fig. 1 backup the conclusion [14] that the change of the PU-to-PMMA ratio from 70:30 to 50:50 causes the increase of the rate of the formation of PU and PMMA in all of the semi-IPNs being studied. The increase of the urethane component formation rate is induced by the decreased dilution of the semi-IPN system resulting in the increase of the probability of interaction of reacting end $\mathrm{NCO}$ and $\mathrm{OH}$ groups of the macrodiisocyanate and the cross-linking agent, respectively. The accelerated polymerization of MMA is induced by the increase of the initial viscosity of the semi-
IPN system resulting in the suppressed mobility of the propagating PMMA macro radicals and therefore in the decrease of the termination constant $\left(k_{t}\right)$, which is inversely proportional to the polymerization rate [15]:

$$
V_{p}=k_{p} \sqrt{\frac{2 f k_{i}}{k_{t}}}[M] \sqrt{[I]}
$$

where $V_{p}$ is the polymerization rate, $k_{p}$ is the propagation constant, $k_{i}$ is the initiation constant, $k_{t}$ is the termination constant, $f$ is the efficiency of the polymerization initiator, $[\mathrm{M}]$ is the concentration of the monomer, and $[\mathrm{I}]$ is the concentration of the polymerization initiator.

Fig. 1 shows that the effect of various metal chelates on the rate of the formation of PU and PMMA in the semi-IPN system does not depend on the ratio between the components content in the initial reaction mixture. The presence of such $\beta$-diketonates as $\mathrm{Fe}(\mathrm{acac})_{3}$ and $\mathrm{Cu}(\text { eacac })_{2}$ in all cases accelerates the process of the 
formation of the semi-IPNs, and the presence of $\mathrm{Cr}(\mathrm{acac})_{3}$ always retards this process as compared with the metalfree semi-IPN. As it was demonstrated in [13], the changes in the rate of the formation of PU and PMMA are caused by the changes of the kinetic characteristics of the formation of $\mathrm{PU}$. Both $\mathrm{Fe}(\mathrm{acac})_{3}$ and $\mathrm{Cu}(\text { eacac })_{2}$ are active catalysts in urethane formation processes [6] so their presence in the forming semi-IPN induces considerable increase of the rate of the formation of PU network. As a result, significant increase of the viscosity of the semiIPN system leads to accelerated MMA polymerization due to the decrease of the termination reaction rate [15].

The comparison of the characteristics obtained for the semi-IPNs with different PU-to-PMMA ratios but with the same metal chelate demonstrate more intensive influence (acceleration or deceleration) of the $\beta$-diketonate on the formation of semi-IPN in the system with the PUto-PMMA ratio of 70:30.

It is worth noting that during formation of semiIPN with the PU-to-PMMA ratio of 70:30 in the presence of $\mathrm{Cr}(\mathrm{acac})_{3}$ the rate of the PU network formation exceeds the rate of the polymerization of MMA practically during the whole period of the experimental analysis (more than $10 \mathrm{~h}$ ). On the contrary, during formation of semi-IPN with the PU-to-PMMA ratio of 50:50 the rate of the MMA polymerization exceeds the rate of PU network formation after $5 \mathrm{~h}$.

The results of the kinetic study demonstrate that the introduction of $\mathrm{Fe}(\mathrm{acac})_{3}$ and $\mathrm{Cu}(\text { eacac) })_{2}$ increases the reaction rates while introduction of chromium acetylacetonate $\left(3^{+}\right)$decreases these rates.

The more distinct effect of iron, copper, and chromium chelates on the kinetics of semi-IPN formation in the system with the PU-to-PMMA ratio of 70:30 may be due to the greater content of the urethane component in this system.

\subsection{Formation of Complexes of Iron, Copper, and Chromium $\beta$-Diketonates with PU and PMMA in Semi- Interpenetrating Polymer N etworks}

As was shown earlier [9], other factors that affect the properties of semi-IPN systems are associated with the complexation processes involving the participation of metal chelates and electron-donor groups of both components of the semi-IPN system.

In the semi-IPN based on linear PMMA and crosslinked $\mathrm{PU}$ and containing $\mathrm{Cu}\left(2^{+}\right), \mathrm{Cr}\left(3^{+}\right)$, or $\mathrm{Fe}\left(3^{+}\right)$ chelates, the $>\mathrm{C}-\mathrm{O}-\mathrm{C}>$ and $-\mathrm{N}(\mathrm{H}) \mathrm{C}(\mathrm{O})$ groups of $\mathrm{PU}$ as well as the $-\mathrm{C}(\mathrm{O}) \mathrm{O}$ groups of PMMA can be located in internal and external coordination spheres of metal ion.

The results of the analysis, using paramagnetic probes, obtained for the semi-IPN system with the PUto-PMMA ratio of 50:50 [9] demonstrate that $\mathrm{Cu}\left(2^{+}\right)$and
$\mathrm{Fe}\left(3^{+}\right)$chelates form complexes with donor groups of both PU and PMMA. According to IR-spectroscopy and EPR-spectroscopy data, this complexation facilitates the interpenetration of PU and PMMA components, decreases the degree of the phase separation between PU and PMMA, and extends the interphase region. Contrary, $\operatorname{Cr}\left(3^{+}\right)$chelate forms complexes mainly with the ether component of PU and stimulates the PU phase isolation.

To estimate the effect of such activators as metal chelates on the components compatibility in semi-IPN with various PU-to-PMMA ratios the complexation processes caused by metal-containing modifiers as well as polymer matrix mobility of the semi-IPN were analyzed by EPR spectroscopy using various paramagnetic probes. The results of the analysis obtained for the semi-IPN with the PU-to-PMMA ratio of 70:30 were compared with the results for the system with the PU-to-PMMA ratio of 50:50.

The representative EPR spectra obtained are illustrated in Fig. 2. The calculated values of the correlation time for nitroxyl spin probe and electron-spin parameters of complex probe are presented in Tables 1 and 2, respectively.

The detailed analysis of spin probe EPR spectra shape and structure for semi-IPNs with the PU-to-PMMA ratio of 50:50 is given in [9]. Here we analyze the complexation in semi-IPNs of various composition using calculated parameters $-\tau, g_{\|}, A_{\|}$and $g_{0}$.

The rotational mobility of nitroxyl probe in the polymer is determined by the structure and mobility of the polymer matrix surrounding the probe. As it is clear from the data in Table 1, the introduction of metal chelate into isolated PU network or linear PMMA in all cases is accompanied by the decrease of the probe rotational mobility ( $\tau$ increases) that indicates the increased density and/or rigidity of the polymer matrix due to the formation of additional network of coordination bonds.

In the semi-IPN system consisting of incompatible PU and PMMA components, the effect of metal chelate on the nitroxyl mobility depends on the central ion of the chelate.

For the semi-IPNs with the PU-to-PMMA ratios both 50:50 and 70:30 the values of the correlation time $(\tau)$ can be ranged as follows:

$$
\tau_{C r}<\tau_{\text {metal free }}<\tau_{C u}<\tau_{F e}
$$

The relative increase of TEMPO rotational mobility in the semi-IPNs with the PU-to-PMMA ratio of 70:30 is possibly due to the decrease of the relative PMMA fraction in the system.

It should be noted, that the precision of $\mathrm{g}_{11}$ determination under the used radio spectroscopy conditions is of 0.001 . The reference compounds used for calibration have $g$-factor values equal to 2.0036 (DPPH) and 2.0015 

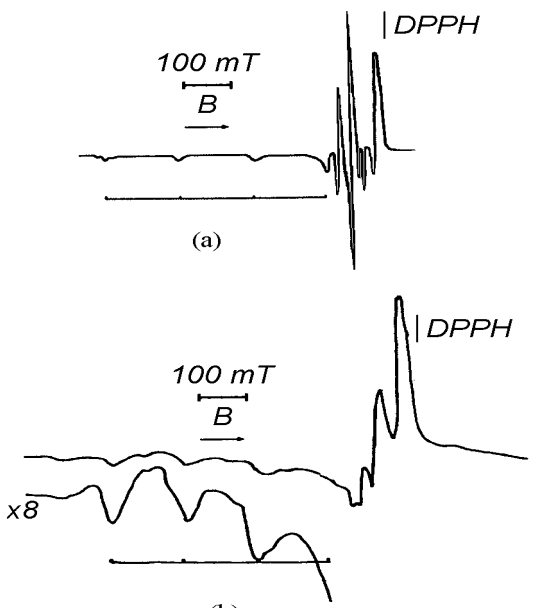

(b)
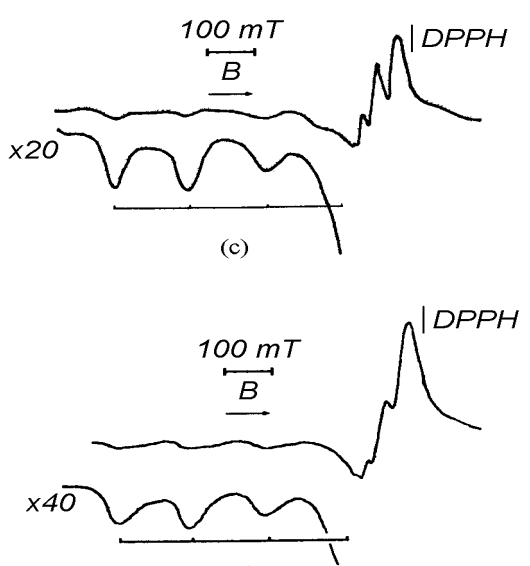

(d)

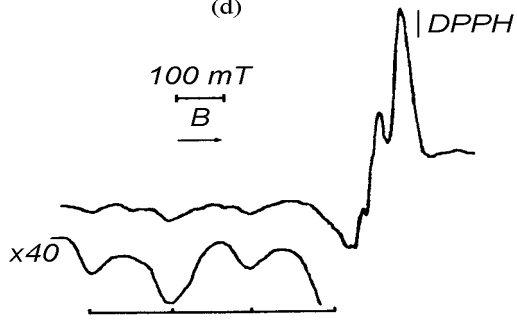

(e)
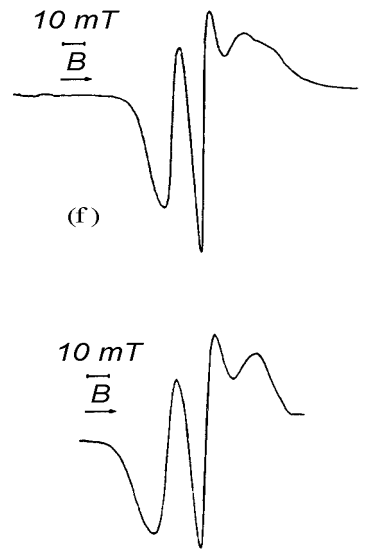

(g)

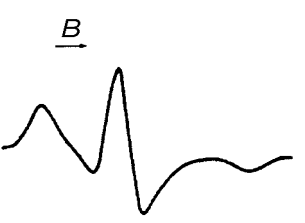

(h)

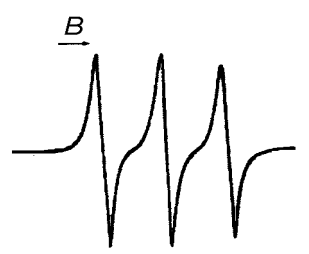

(i)

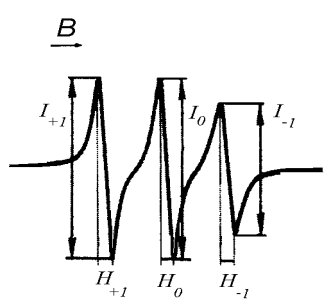

(j)

Fig. 2. EPR-spectra of complex (a-e) and nitroxyl (f-j) spin probes in various media: $\mathrm{Cu}(\mathrm{eacac})_{2}$ diamagnetically isolated in glassy (77 K) chloroform-toluene mixture, not forming complexes with the metal chelate [12] (a), $\mathrm{Cu}\left(\right.$ eacac) ${ }_{2}$ in metal free 50/ 50 semi-IPN (b), $\mathrm{Cu}(\text { eacac) })_{2}$ in Fe(acac) $)_{3}$ containing 50/50 semi-IPN (c), $\mathrm{Cu}(\text { eacac) })_{2}$ in metal free 70/30 semi-IPN (d),

$\mathrm{Cu}\left(\right.$ eacac) ${ }_{2}$ in $\mathrm{Cr}(\mathrm{acac})_{3}$ containing 70/30 semi-IPN (e); TEMPO in metal free 50/50 semi-IPN (f), TEMPO in metal free 70/30 semi-IPN (g), calculated spectra of TEMPO in the range of slow (h) and fast (i) rotational motion [11]; TEMPO EPRspectrum components assignment $(\mathrm{j})$.

$\left(\mathrm{Mn}^{2+}\right.$ doped $\left.\mathrm{MgO}\right)$; free electron $g$-factor has the value of 2.0023. When complex formation occurs with axial coordination of ligand, then $g_{\|}$- value changes in the narrow range from 2.2 to 2.4 [7]. Thus we can consider the electron-spin parameter changes not less than 0.002 as noticeable and changes not less than 0.010 as significant. Undisturbed $\mathrm{Cu}\left(2^{+}\right)$ethyl acetoacetate and immobilized in situ in semi-IPN matrix $g_{\|}$-factor values are equal to 2.243 and 2.246, correspondingly. As HFS-constant simultaneously decreases by $20 \cdot 10^{-4} \mathrm{~cm}^{-1}$ we can suppose that the changes of the above parameters are sufficiently noticeable to confirm complex formation of the modifier with electron donating group. Likewise $g_{\|}$- value changes of the probe introduced into the $\mathrm{Fe}(3+)$ and $\mathrm{Cu}(2+)$ containing semi-IPNs along with the semi-IPNs composition changes indicate significant or noticeable changes of complexing character when changing semi-IPN with PU/PMMA $=50 / 50$ to semi-IPN with 
Table 1

Correlation time of nitroxyl paramagnetic probe rotational diffusion in semi-IPNs, PU and PMMA

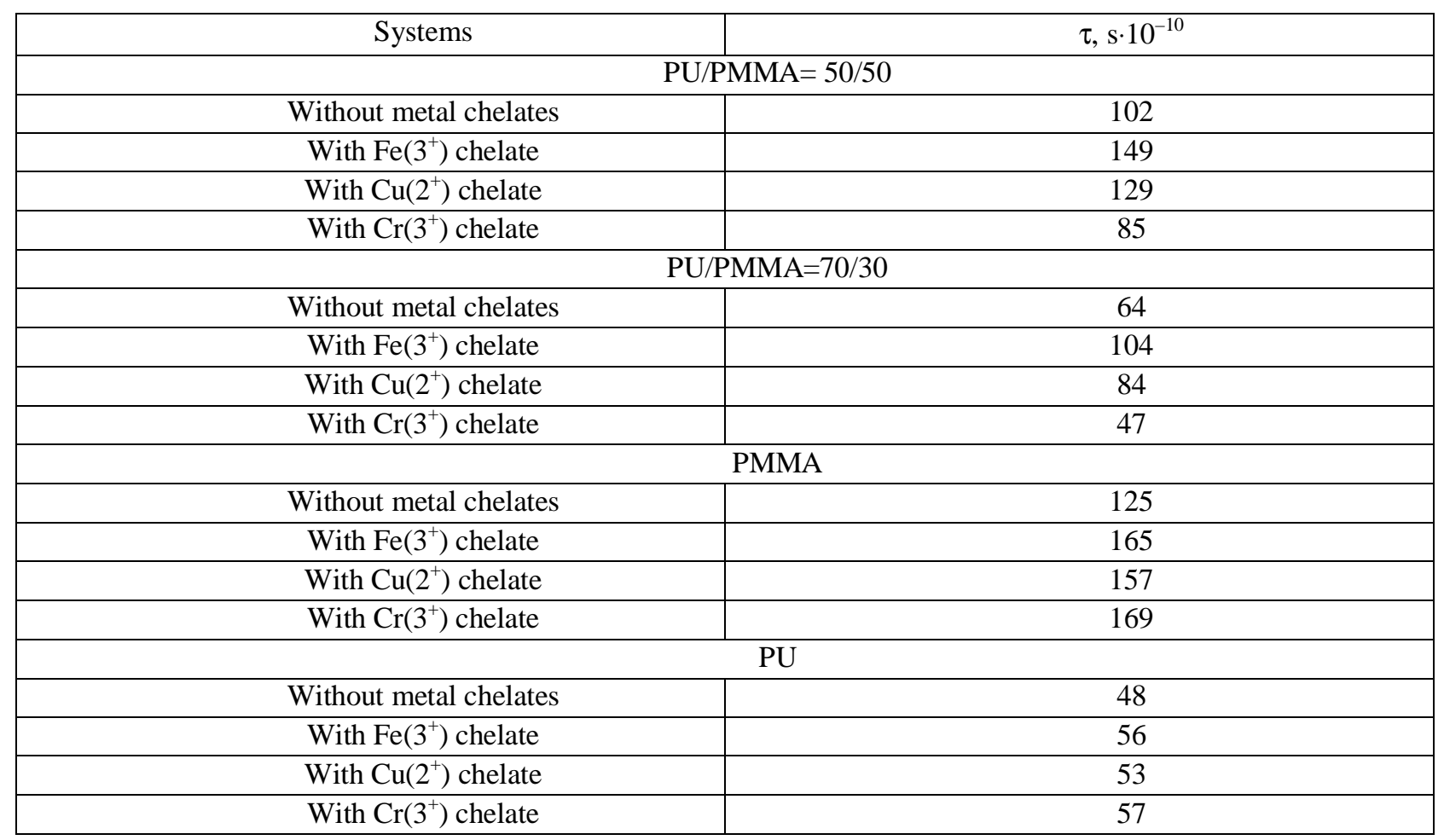

Electron - spin parameters of copper-containing complex paramagnetic probe in various media

\begin{tabular}{|c|c|c|c|}
\hline Semi-interpenetrating polymer network & $\mathrm{g}_{\|}$ & $\mathrm{A}_{\|} \cdot 10^{-4} \mathrm{~cm}^{-1}$ & $\mathrm{~g}_{0}$ \\
\hline \multicolumn{4}{|l|}{ PU/PMMA = 50/50 } \\
\hline Without metal chelates: & 2.273 & 164 & 2.119 \\
\hline With $\mathrm{Fe}\left(3^{+}\right)$chelate: & 2.267 & 171 & 2.117 \\
\hline With $\mathrm{Cu}\left(2^{+}\right)$chelate: & 2.273 & 164 & 2.116 \\
\hline With $\mathrm{Cr}\left(3^{+}\right)$chelate: & 2.284 & 164 & 2.123 \\
\hline \multicolumn{4}{|l|}{ PU/PMMA = 70/30 } \\
\hline Without metal chelates: & 2.277 & 169 & 2.134 \\
\hline With $\mathrm{Fe}\left(3^{+}\right)$chelate: & 2.277 & 169 & 2.131 \\
\hline With $\mathrm{Cu}\left(2^{+}\right)$chelate: & 2.271 & 169 & 2.129 \\
\hline With $\operatorname{Cr}\left(3^{+}\right)$chelate: & 2.283 & 170 & 2.133 \\
\hline 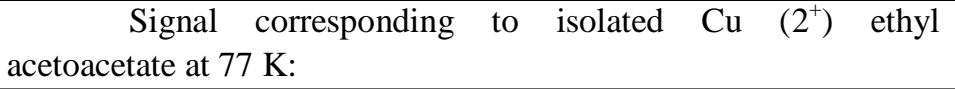 & 2.243 & 192 & 2.113 \\
\hline
\end{tabular}

* The isotropic value $\left(g_{0}\right)$ of the $g$-factor was calculated by the following equation: $g_{0}=\left(g_{\|}+2 g_{\perp}\right) / 3$.

$\mathrm{PU} / \mathrm{PMMA}=70 / 30$. Electron-spin parameters of the complex probe in the $\mathrm{Cr}(3+)$ containing semi-IPN remain practically unchanged if the relative urethane fraction increases.

This result corresponds to the data that demonstrate the predominant bonding of $\mathrm{Cr}(\mathrm{acac})_{3}$ with the polyester component of PU independently of the PU fraction in the semi-IPN. In both the semi-IPN systems with the PU-toPMMA ratios of $70: 30$ or of 50:50, such predominant bonding facilitates the isolation of PU and the phase separation.

In the $\mathrm{Fe}(3+)$ or $\mathrm{Cu}(2+)$ containing semi-IPN with the PU-to-PMMA ratio of 70:30 the probe can interact react with stronger complexing agents as compared with the semi-IPN with the PU-to-PMMA ratio of 50:50. This is due to excess of PU with higher donor ability in the system with the PU-to-PMMA ratio of 70:30. 


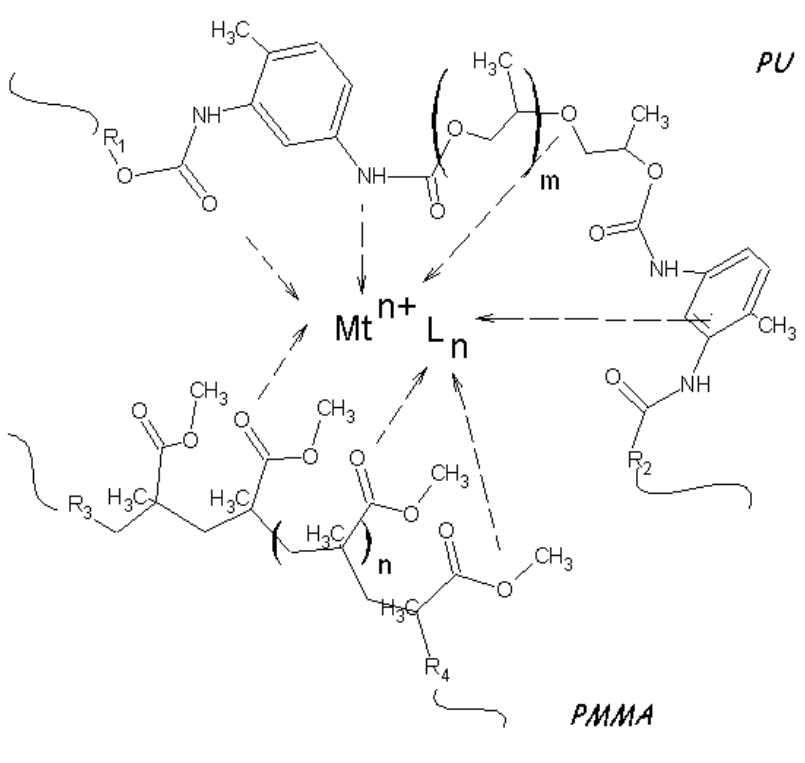

a

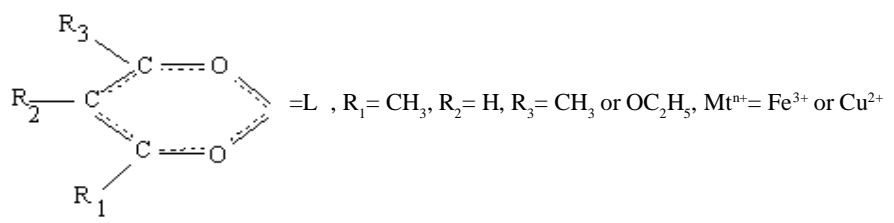

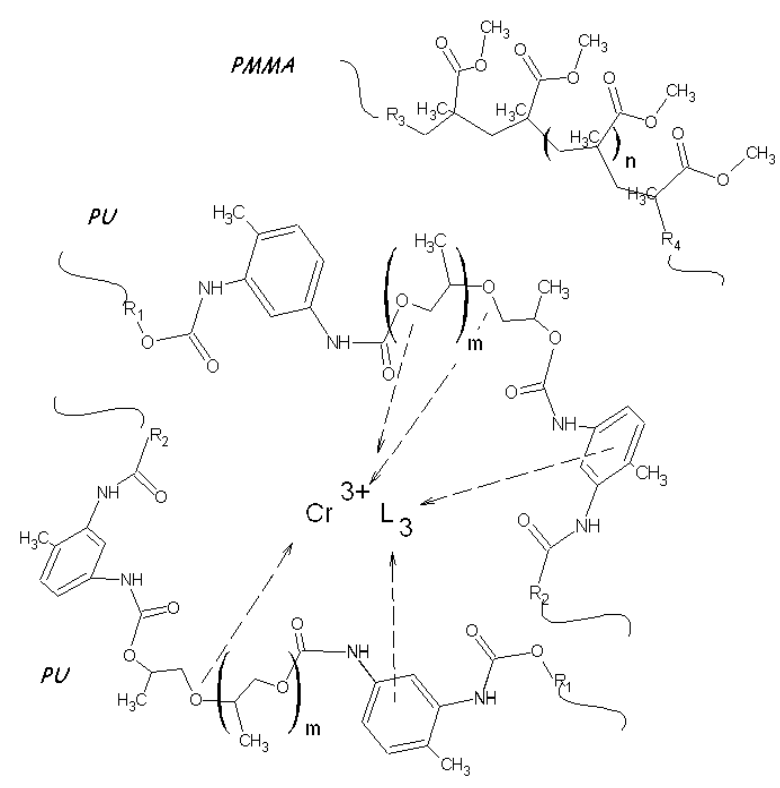

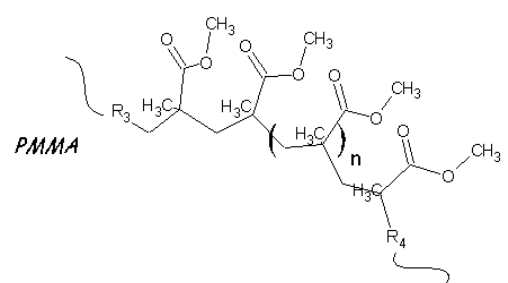

b

Fig. 3. Complexes in semi-IPNs with PU/PMMA ratio of 50:50 containing metal chelates in an amount of $1 \%$ by weight: $\mathrm{Fe}(\mathrm{acac})_{3}$ or $\mathrm{Cu}(\text { eacac })_{2}$ (a) and $\mathrm{Cr}(\mathrm{acac})_{3}$ (b)

The data in Table 2 indicate the greater effect of metal ion type on the semi-IPN system with the PU-toPMMA ratio of 50:50 as compared with the system with the PU-to-PMMA ratio of 70:30. In other words, the system with the PU-to-PMMA ratio of 70:30 is less sensitive to the change of the metal ion type. The values of parameters $g_{\|}, A_{\|}$for all complexes in the semi-IPNs with the PU-toPMMA ratio of 70:30 are characteristic for the complexes that are bound predominantly with the PU component [9]. This fact agrees with increased PU fraction in 70/30 semiIPN.

The regularities obtained are evident from the proportion of various polar groups in the system: $-\mathrm{N}(\mathrm{H}) \mathrm{C}(\mathrm{O}) \mathrm{O}$ urethane groups and $>\mathrm{C}-\mathrm{O}-\mathrm{C}<$ ether groups of the PU network, and also $-\mathrm{C}(\mathrm{O}) \mathrm{O}$ ester groups of PMMA. The polar groups content ratio is 1:8.72:6.25 for 50:50 semi-IPN and 1:8.91:2.73 for 70:30 semi-IPN.

In the semi-IPN with the PU-to-PMMA ratio of 50:50, one urethane group corresponds approximately to equal numbers of ether and ester groups. Complexes of copper and iron $\beta$-diketonates formed with urethane (PU) and ester groups (PMMA) are more favorable and stable due to higher electron-donor ability of urethane and ester groups as compared with ether groups [16]. The formation of metal chelate complexes with both of the semi-IPNs components facilitates the interpenetration of PU and PMMA in the presence of metal chelates.

In the semi-IPN system with the PU-to-PMMA ratio of 70:30 one urethane group corresponds to three times more ether groups (PU) than ester groups (PMMA). As a result, the probability of the formation of complexes of metal chelate with the urethane and ether groups of PU in such system is higher than the probability of the formation of complexes with the polar groups of both the PU and PMMA components as compared with the system with the PU-to-PMMA ratio of 50:50.

Fig. 3 illustrates possible complexes of metal chelate in the semi-IPN with the PU-to-PMMA ratio of 50:50. Complex (b) is also characteristic for all metal chelates in the system with the PU-to-PMMA ratio of 70:30.

The differences in the complexation of iron, copper, and chromium chelates in the semi-IPNs with the PU-toPMMA ratio of 50:50 can be due to the differences in the electron configuration of the central metal ion of the metal 
chelate. Metal ion electron configuration facilitates formation of complexes with specific geometric characteristics that can be realized with consideration for the flexibility of a possible macro ligand $[8,17]$. In addition, according to the existing classification [17] iron and copper belong to the same type of acceptors while chromium belongs to a different one. The differences between the formation of complexes of iron and copper salts and complexes of chromium salts with hydroxyl groups of polysaccharides were discussed in [18]. At the present time, it is impossible to explain exactly the characteristic properties of complexing processes with the participation of metal chelates studied in the semi-IPN with the PU-toPMMA ratio of 50:50. It can be suggested that the independence of the complexing process on metal chelate type in the semi-IPN with the PU-to-PMMA ratio of 70:30 is caused by the increase of the fraction of ether-containing flexible component.

\section{Conclusions}

The results of the study demonstrate that the kinetics of formation of PU and PMMA in semi-IPN systems depends on the type of metal chelate introduced in the system, as the interaction between the system components and the metal chelate depends on the type of the metal ion. Introduction of $\mathrm{Fe}(\mathrm{acac})_{3}$ and $\mathrm{Cu}(\text { eacac })_{2}$ promotes the formation of the semi-IPN system components whereas introduction of $\mathrm{Cr}(\mathrm{acac})_{3}$ retards this process, independently of the composition of the system. These characteristics are more expressed for the semi-IPN systems with the PU-to-PMMA ratio of 70:30.

On the other hand the system composition determines macro ligand selection (PU or PMMA) during complex formation with metal chelates. In semi-IPN with PU-to-PMMA ratio of 50:50 $\mathrm{Fe}(\mathrm{acac})_{3}$ and $\mathrm{Cu}$ (eacac) form complexes both with PU and with PMMA component whereas $\mathrm{Cr}(\mathrm{acac})_{3}$ forms complexes mainly with $\mathrm{PU}$ component. This facilitates the interpenetration of $\mathrm{PU}$ and PMMA in the presence of $\mathrm{Fe}(3+)$ and $\mathrm{Cu}(2+)$ metal chelates. In semi-IPN with PU-to-PMMA ratio of 70:30 all analyzed metal chelates form complexes predominantly with the PU component, which facilitates the isolation of $\mathrm{PU}$ and the phase separation.

As it was demonstrated in $[9,13]$ for some metalcontaining semi-IPNs influence of reaction kinetics on the phase separation in the system can be intensified due to complexation of the metal chelates with the system components. According to the data obtained for semi IPNs with varying PU and PMMA content the supposition can be made that in the presence of metal chelates in semiIPNs either synergetic or an opposite effect of reaction kinetics and complex formation on phase separation can be realized, depending on PU-to-PMMA ratio.

\section{References}

[1] Lipatov Yu.: Vzaimopronikaushchie polimernye setki s razdelennymi phazami. Dnepropetrovsk 2001.

[2] Lee J., Ruegg M., Balsara N. et al.: Macromolecules, 2003, 36, 6537.

[3] Aravind I., Albert P., Ranganathaiah C. et al.: Polymer, 2004, 45, 4925.

[4] Jien-Ming H.: J. Appl. Polym. Sci., 2003, 88, 2247.

[5] Alekseeva T., Lipatov Yu., Babkina N. et al.: Polymer, 2005, 46, 319 .

[6] Nizelskii Yu.: Cataliticheskie svoistva $\beta$-diketonatov metalov. Naukova dumka, Kyiv 1983.

[7] Shklyaev A. and Anufrienko V.: Zh. Struct. Khim., 1975, 16, 999.

[8] Kozak N., Kosyanchuk L., Lipatov Yu., et al.: Vysokomol. Soed., 2000, 42(A), 2104.

[9] Lipatov Yu., Kosyanchuk L., Kozak N. et al.: Vysokomol. Soed., 2006, 48(A), 388.

[10] Lipatov Yu., Alekseeva T. and Rosovitsky V.: Doklady Akad. Nauk SSSR, 1989, 307, 883.

[11] Buchachenko A., Kovarskii A. and Vasserman A. [in:] Rogovin Z. (ed.) Study of polymers by the paramagnetic probe methods. Advances in polymer science. Wiley, NY 1974.

[12] Lipatova T. and Nizelskii Yu. [in:] Uspekhi khimii polyuretanov: komplexoobrazovanie i mehanizm cataliza reakcii obrazovanoya uretanov $\beta$-diketonatami medi. Naukova Dumka, Kyiv 1972.

[13] Lipatov Yu., Kosyanchuk L., Babkina N. et al.:Dopovidi Nats. Akad. Nauk Ukrainy, 2005, 7, 134.

[14] Lipatov Yu. and Alekseeva T.: Uspekhi Khimii, 1992, 61, 1203.

[15] Gladyshev G. and Popov V.: Radikalnaya polymerizaziya pri glubokih stepenyah prevrasheniya. Nauka, Moskva 1974. [16] Guryanova E., Goldshtein I. and Romm I.: Donornoakceptornye svyazi. Khimiya, Moskva 1973.

[17] Day M. and Selbin J.: Theoretical inorganic chemistry ( ${ }^{\text {rd }}$ ed.). Reinhold Book Corp., NY-Amsterdam-London 1969. [18] Giesielski W., Lii Ch., Ven M.-T. and Tomasik P.: Carbohydrate Polymers, 2003, 51, 47.

\section{КІНЕТИКА РЕАКЦЇ ТА КОМПЛЕКСО- УТВОРЕННЯ МАКРОМОЛЕКУЛА-ХЕЛАТ МЕТАЛУ У МЕТАЛОВМІСНИХ НАПІВ- ВЗАЕМОПРОНИКНИХ ПОЛІМЕРНИХ СІТКАХ НА ОСНОВІ ЗШИТОГО ПОЛІУРЕТАНУ ТА ЛІНІЙНОГО ПОЛІМЕТИЛМЕТАКРИЛАТУ}

Анотація. Встановлено, щуо відповідно до даних ЕПР та ДСК кінетика формування одночасних напіввзаємо-проникних сіток на основі зиитого поліуретану та лінійного поліметилметакрилату при співвідношенні компонентів як 50:50 так, i 70:30, одержаних у присутності хелатів $3 d$-металів, залежнть від типуметалу. 3 іншого боку, склад сис-теми визначає вибір макроліганду - поліуретан чи полімети-метакрилат при утворенні комплексів з $\beta$-дикетонатами металів.

Ключові слова: одночасні напіввзаємопроникні полімерні сітки, поліуретан, поліметилметакрилат, $\beta$-дикетонати $\mathrm{Fe}(3+), \mathrm{Cr}(3+)$ ma Cu(2+), кінетика реакиіï, комплекс металполімер, ДСК, ЕПР. 